\title{
On the complexities of ceramide changes in cells undergoing apoptosis: lack of evidence for a second messenger function in apoptotic induction
}

\author{
Julian D. Watts ${ }^{\star, 1}$, Ming Gu ${ }^{1,3}$, Scott D. Patterson ${ }^{2}$, \\ Ruedi Aebersold ${ }^{1}$ and Anthony J. Polverino ${ }^{2}$ \\ ${ }^{1}$ Department of Molecular Biotechnology, University of Washington, Seattle, \\ Washington 98195, USA \\ 2 Department of Protein Structure, Amgen Inc., Thousand Oaks, California \\ 91320-1789, USA \\ 3 Present address: Wyeth-Ayerst Research, CN 8000, Princeton, New Jersey \\ 08543-800, USA \\ * corresponding author: Department of Molecular Biotechnology, Box 357730, \\ University of Washington, Seattle, Washington 98195-7730 \\ Email: julian@u.washington.edu. \\ tel: 206-616-2919; fax: 206-685-7301
}

Received: 31.08.98; revised: 24.10.98; accepted 11.11 .98

Edited by R.A. Knight

\begin{abstract}
The generation of cellular ceramides as a second messenger has been implicated as a regulatory and required step for the induction of apoptosis. In this study, we have applied a recently developed mass spectrometric technique to the determination of changes in physiological ceramide levels during apoptosis induced by tumor necrosis factor plus cycloheximide in U937 cells and the chemical agents anisomycin or geranylgeraniol in HL-60 cells. The mass spectrometric method has significant advantages over traditional methods for ceramide quantitation in that it determines the relative abundance of all ceramide species present in complex biological lipid mixtures individually and simultaneously. We quantitiated ceramides ranging from $\mathrm{C} 14$ to $\mathrm{C} 26$, finding that their basal levels and relative distribution varied significantly, both within and between different cell types. However, we were not able to detect any significant changes in either total ceramide content or species distribution until $1 \mathrm{~h}$ or more post-stimulation with any of these treatments, by which time the cells were in an advanced stage of apoptosis. Differences were also seen between all three treatments in the ceramide species distribution observed in these late stages of apoptosis. These data indicate that in vivo ceramide generation occurs as a consequence of apoptosis rather than as an essential second messenger involved in its induction. They also pose new questions about the potential roles that certain ceramide species may play in the late stages of apoptosis, and demonstrate a clear need to utilize the resolving power of mass spectrometry-based assays in any future investigations into the biological function of ceramides.
\end{abstract}

Keywords: mass spectrometry; electrospray ionization; precursor ion scanning; tumor necrosis factor; anisomycin; geranylgeraniol

\begin{abstract}
Abbreviations: Aniso, anisomycin; $\mathrm{CHX}$, cycloheximide; DAG, diacylglycerol; DTT, dithiothreitol; ECL, enhanced chemiluminescence; GG, geranylgeraniol; mAb, monoclonal antibody; MS, mass spectrometry; $m / z$, mass to charge ratio; PARP, poly (ADP-ribose) polymerase; PMSF, phenylmethylsulfonyl fluoride; PIS, precursor ion scanning; SMase, sphingomyelinase; STI, soybean trypsin inhibitor; TNF, tumor necrosis factor
\end{abstract}

\section{Introduction}

Apoptosis, or programmed cell death, is a term used to describe a distinct set of morphological and biochemical changes that define a eukaryotic cell death pathway that is well conserved throughout evolution. ${ }^{1,2}$ Apoptosis plays an essential role in controlling a variety of cellular processes including proliferation, differentiation and development, and by a variety of means can be initiated in all eukaryotic cell types and tissues. There has thus been considerable interest in the elucidation of apoptotic signaling pathways and the identification of any potential second messengers which might regulate them.

Ceramides are a group of neutral sphingolipids, and are among some of the most non-polar molecules present in living tissue. They also constitute the most diverse group of biological lipid molecules, and despite their discovery over a century ago, have proven difficult to study from a functional biological standpoint, due in large part to their apolar nature. ${ }^{3}$ Recently, however, the sphingosine-based subgroup of ceramides has attracted considerable attention as a potential second messenger in the regulation of apoptosis. ${ }^{4,5}$ Using a variety of indirect quantitative assays, it has been reported that such ceramides can be rapidly generated (within $5 \mathrm{~min}$ ) by stimulation of a variety of cell surface receptors, including those for tumor necrosis factor (TNF), ${ }^{6,7} \mathrm{Fas}^{8-10}$ and interleukin-1, ${ }^{11}$ under conditions which also induced apoptosis. Other studies found that membrane-associated acidic and/or neutral sphingomyelinases (SMase), which can hydrolyze membrane sphingomyelin to produce ceramide, are also rapidly activated by stimulation of the same receptors. ${ }^{12,13}$ Additionally, the ability of the synthetic, non-naturally occurring ceramide, $\mathrm{N}$ acetyl-D-erythro-sphingosine (C2:0 ceramide) to induce apoptosis has been well documented. Thus on the strength of these observations it has been postulated that ceramide functions as a critical second messenger in the regulation of signal transduction via these receptors, leading to apoptosis. $^{4,5}$ 
Apoptosis can also be induced by means other than receptor stimulation. A number of forms of stress, both physical and chemical, have been shown to elicit an apoptotic response in a wide range of cell and tissue types, a number of which have also been shown to elicit ceramide generation. Forms of stress which have been shown to induce both apoptosis and ceramide generation include ionizing radiation ${ }^{14-16}$ and UV radiation. ${ }^{15,16}$ Furthermore, a number of chemical agents have also been shown to be capable of inducing apoptosis. These include compounds such as daunorubicin, ${ }^{17,18}$ anisomycin (Aniso), ${ }^{19,20}$ geranylgeraniol $(\mathrm{GG})^{20-22}$ and farnesol ${ }^{23}$ to name but a few. At least one of these, daunorubicin, has also been reported to elicit in vivo ceramide generation. ${ }^{17,18}$ Searches for potential physiological targets for ceramides has led to the identification of a number of potential ceramide-activated protein kinases and phosphatases, though information on how these might fit into apoptotic signaling pathways remains limited. ${ }^{5}$

We recently developed a mass spectrometry (MS) based assay for the direct quantitation of ceramides present in the highly complex lipid mixtures obtainable from eukaryotic cells. ${ }^{24}$ This method has many advantages over those commonly used for ceramide quantitation. In particular, it involves direct measurement from lipid extracts, not requiring enzymatic assays or TLC separations. It also effectively resolves and quantitates each individual ceramide species present in the sample simultaneously, an advantage only afforded by MS-based assays. We previously applied this method to study Fas-induced apoptosis in Jurkat cells, determining that when so measured, no significant generation of ceramide occurred at any time during this process, early or late. ${ }^{25}$

In this paper, we have investigated some other wellcharacterized experimental systems for studying apoptosis: the treatment of U937 cells with TNF and cycloheximide (CHX), and HL-60 cells with either Aniso or GG. Consistent with our earlier studies, we again found, in each case, that there was no rapid generation of intracellular ceramides, as would be expected for a second messenger function. However, we did find that ceramide generation occurred late in the apoptotic process, and quite surprisingly that the induced variations in the individual ceramide species distribution observed were different for each of the stimuli employed. While these data clearly indicate that in vivo ceramide generation does not occur as an early signal for apoptosis, they do raise interesting questions about the role individual ceramide species might play in the late stages of apoptosis. These data also demonstrate the need to take advantage of the great sensitivity and resolving power afforded by MS-based assays in any future investigations into the biological implications of ceramide generation.

\section{Results}

We initially chose to study the induction of apoptosis by TNF plus $\mathrm{CHX}$ in U937 cells since this system has been used extensively to study both TNF-induced apoptosis and ceramide generation. $\mathrm{CHX}$ is a protein synthesis inhibitor, typically added to cell cultures when TNF-induced apoptosis is under investigation, since this does not occur in most cell types in the absence of $\mathrm{CHX}$. While the mechanism for this process is not clear, it is believed that the inhibition of TNFinduced survival gene expression and translation (most likely including NF- $\kappa \mathrm{B}$ ) is responsible for this effect. ${ }^{26}$ We initially examined a number of known apoptotic markers in order to confirm the induction of apoptosis by TNF and CHX, and to determine the time-frame for this process. Morphological examinations of the cells showed that membrane blebbing and chromatin condensation were already evident at $60 \mathrm{~min}$ post-stimulation, with almost all cells displaying such morphological characteristics at $120 \mathrm{~min}$. Cells treated for the same periods of time with $\mathrm{CHX}$ alone did not exhibit these morphological characteristics (not shown).

In order to more accurately evaluate the apoptotic state of the cells at each time point, we assessed by immunoblotting the proteolytic cleavage of the caspase target poly (ADP-ribose) polymerase (PARP), as well as cleavage of the apoptotic proteases caspase-3 (CPP32) and caspase- 8 (MACH $\alpha 1 /$ FLICE). Proteolytic processing of caspases is a required step for their activation. ${ }^{27,28}$ As can be seen in Figure 1, we were able to detect PARP cleavage 60 min after the addition of TNF and $\mathrm{CHX}$, with little full-length PARP remaining at $120 \mathrm{~min}$. Immunoblotting for caspase-3 revealed its cleavage (and presumed activation) at $120 \mathrm{~min}$ post-stimulation, though there was no detectable cleavage at $60 \mathrm{~min}$. Since the TNF-induced caspase pathway leading to apoptosis has been postulated to involve caspase-8, we also immunoblotted for this enzyme. While the antibody used did not recognize the cleaved form it did recognize both splice variants of the enzyme and clearly showed depletion of full-length caspase-8 at $120 \mathrm{~min}$ post stimulation. It also appeared that full-length caspase-8 might have been reduced at $60 \mathrm{~min}$, but without being able to detect the cleaved form, it was not possible to be certain of this on the strength of these data alone. As a final test to confirm that the observed decline in caspase- 8 was not a sample loading effect or due to a general loss or degradation of total cellular protein, the caspase-8 blot was re-probed with an anti-actin $\mathrm{Ab}$. As can be also seen from Figure 1, the levels of actin remain constant throughout the course of the experiment, additionally confirming that the observed cleavage of caspase-8, as well as PARP and caspase-3, is a specific apoptotic response. It is thus clear from these data that the U937 cells are entering the late stages of apoptosis at $60 \mathrm{~min}$ post-TNF stimulation, with nearly all cells being in such late stages at $120 \mathrm{~min}$.

We next wanted to evaluate any variations in ceramide content which might be occurring in these cells. Our approach to this was to use a triple quadrupole mass spectrometer and a technique known as precursor ion scanning (PIS) to isolate ceramide-specific signals from the highly complex lipid mixtures obtainable from biological sources. The method works by scanning across a preset range of mass to charge ratios $(\mathrm{m} / \mathrm{z})$ in the first quadrupole and successively fragmenting each ion by collision with argon gas in the second quadrupole, a process known as collision-induced dissociation. The generation of a ceramide-specific fragment ion at $m / z \approx 264$ derived from the 
sphingosine group, common to all sphingosine-based ceramides, regardless of chain length is then recorded in the third quadrupole. ${ }^{24}$ The data system then displays the $m / z$ values of only those ions which yielded the $m / z \approx 264$ fragment ion. Furthermore, due to a tendency to loose a water molecule as a result of collisions occurring at the ion source, each ceramide species yields two characteristic peaks separated by 18 mass units. ${ }^{24}$ This process acts as an additional confirmation of ceramide identity. Finally, by adding synthetic C2:0 ceramide (which does not occur naturally in mammalian cells) to a fixed concentration as an

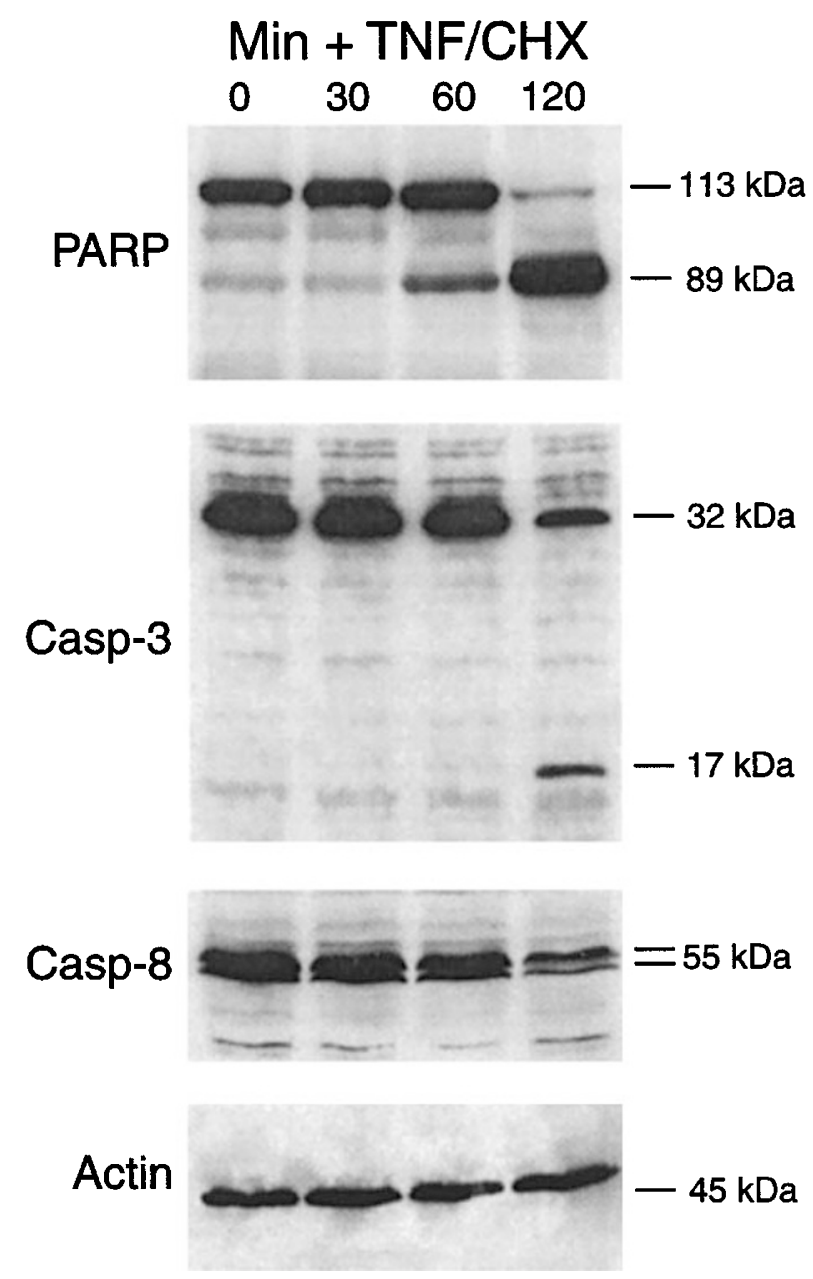

Figure 1 Cleavage of PARP, caspase- 3 and caspase- 8 in TNF and cycloheximide co-stimulated U937 cells. U937 cells $\left(2 \times 10^{6} / \mathrm{ml}\right)$ were stimulated at $37^{\circ} \mathrm{C}$ with $1 \mu \mathrm{g} / \mathrm{ml} \mathrm{CHX}$ and $20 \mathrm{ng} / \mathrm{ml}$ TNF for the indicated times. Cell lysates were prepared as described in Materials and Methods. Lysate equivalent to $7.5 \times 10^{5}$ cells or $1 \times 10^{6}$ cells were subjected to SDS PAGE on $8 \%$ (for PARP) and $15 \%$ gels (for caspases) respectively prior to transfer to nitrocellulose membranes. Immunoblotting was performed as indicated with anti-PARP, anti-caspase-3 (Casp-3),anti-caspase-8 (Casp-8) mAbs, as described in Materials and Methods. Visualization was by ECL. Bands corresponding to the full length and cleaved forms of PARP (113 and $89 \mathrm{kDa})$, caspase-3 (32 and $17 \mathrm{kDa})$, caspase- $8(55 \mathrm{kDa})$ are indicated where appropriate. As a control for protein loading, the caspase- 8 blot was stripped and reprobed with an anti-actin $A b$, as described in Materials and Methods. Vizualization was again by ECL, with the actin migrating at an apparent molecular weight of $45 \mathrm{kDa}$ internal standard, relative variations in ceramide levels and species distribution can be monitored from one sample to the next.

U937 cells were thus stimulated for $0,5,30,60$ and 120 min with TNF and $\mathrm{CHX}$ as before. Lipid extracts were then prepared and PIS performed as previously described. ${ }^{24,25}$ Each data set was then normalized to the C2:0 internal standard signal at $m / z \approx 324$ (C2:0 minus one water molecule) to facilitate visual interpretation of the data. Figure 2 shows representative PIS data for one each of the 0 min (panels A and B), 5 min (panels $C$ and D) and 120 min (panels $E$ and $F$ ) time points. The predominant ceramide species present in the U937 cells were found to be the C16:0, C24:1 and C24:0 (see panels A, C and E). We could also clearly distinguish several minor ceramide species, namely the C14:0, C18:0, C20:0, C22:1, C22:0 and C26: 1 (shown in panels $B, D$ and $F$, which represent tenfold enlargements of the shaded regions indicated in panels $A, C$ and $E$, respectively). By comparing panels $A$ to $C$ and $B$ to $D$, it is clear that at 5 min there is no increase in the cellular level of any of the measurable ceramide species. Repeat experiments which additionally included 2 and 10 min time-points produced similar results (data not shown). By comparing panels $A$ to $E$ and $B$ to $F$, however, it can be seen that the ceramide species distribution does change at 120 min post-stimulation, with some (though not all) ceramide species appearing to increase in level relative to the $\mathrm{C} 2: 0$ signal. It is also clear that there was no generation of any previously undetected ceramide species following cell stimulation at any time (Figure 2 and data not shown).

In order to present such data more clearly, the signal intensities (i.e. peak area) for the two peaks generated by each ceramide species (indicated in Figure 2) were summed and again normalized to the $\mathrm{C} 2: 0$ signal. The signal ratio of each detected ceramide species to the C2:0 was calculated, means derived, and the data presented graphically. As can be seen from Figure 3, of the major ceramides present in U937 cells, the C16:0 remained unchanged up to 60 min post-stimulation with TNF and $\mathrm{CHX}$. However, the C16:0 level had increased at $120 \mathrm{~min}$. Figure 4 shows that a similar response was observed for the C14:0, C18:0, C20:0 and C22:1 minor ceramide species. It was also apparent from these data that the C22:0, C24:1, C24:0 and C26:1 had not increased in level, even at $120 \mathrm{~min}$, and had in fact declined in level over the course of the stimulation. However, control samples of cells treated with $\mathrm{CHX}$ alone for $120 \mathrm{~min}(\mathrm{Ctl})$ suggested that these observed declines in level were likely due to the action of $\mathrm{CHX}$ on the cells rather than TNF. It should be noted that treatment of $U 937$ cells with $\mathrm{CHX}$ alone did not induce apoptosis over the time frame of these experiments (data not shown). Thus it can be concluded from Figures 1-4 that there is no generation of any ceramides in response to TNF until the U937 cells are well advanced in the apoptotic process.

We next investigated the effects of Aniso and GG on cellular ceramide levels in HL-60 cells. Aniso is a protein synthesis inhibitor, and has been used in a number of studies for its ability to induce apoptosis. ${ }^{19,20} \mathrm{GG}$ is a 


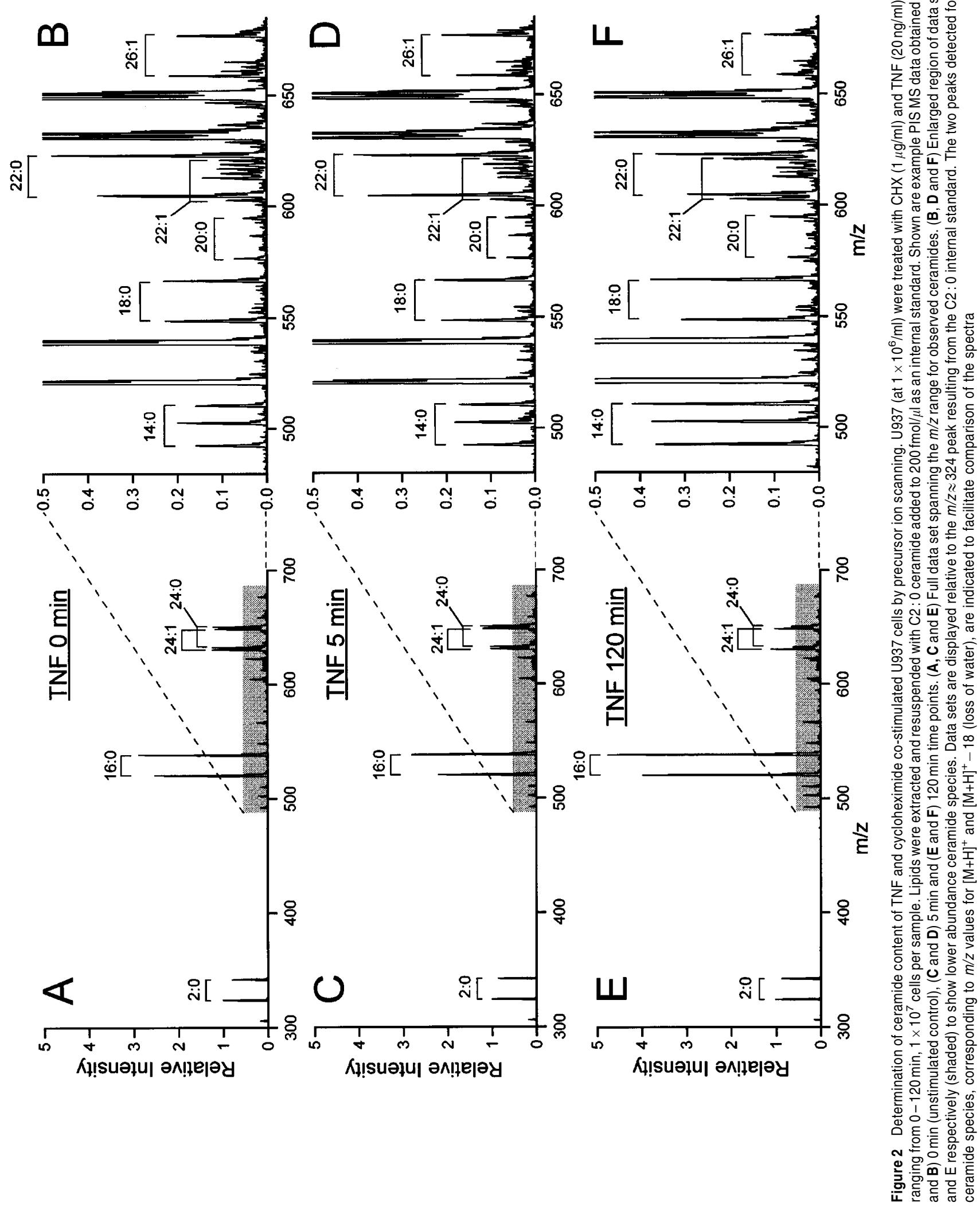


natural lipid product and a component of the cholesterol biosynthesis pathway, and has also been studied previously for its ability to induce apoptosis. ${ }^{20-22}$ Since both of these compounds had previously been used by us for the study of apoptosis in HL-60 cells, lipid samples were thus prepared from identically treated cells, ${ }^{20}$ and again analyzed by MS.

Figures 5 and 6 show that, as was the case with TNF and $\mathrm{CHX}$, Aniso and $\mathrm{GG}$ also failed to induce a rapid increase in cellular ceramide levels. Aniso did not induce
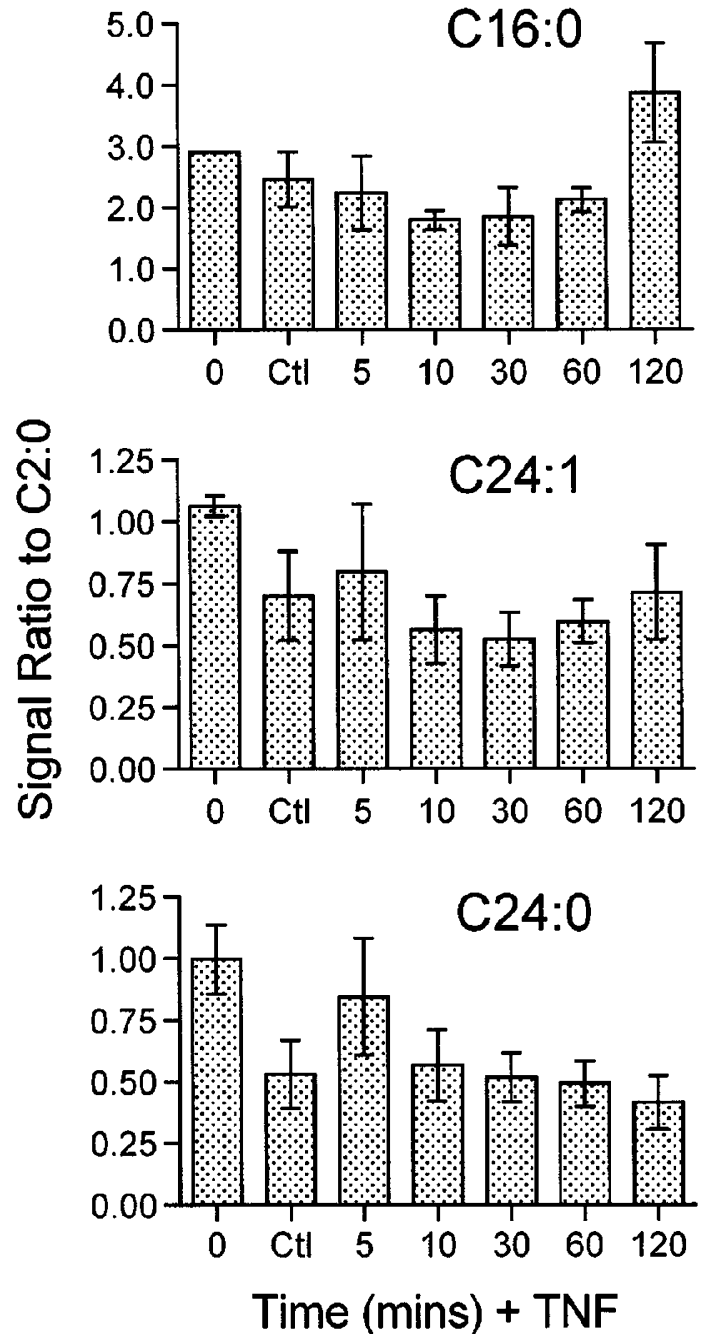

Figure 3 Variation of the predominant cellular ceramide species in U937 cells stimulated with TNF and cycloheximide. U937 (at $2 \times 10^{6} / \mathrm{ml}$ ) were treated with $\mathrm{CHX}(1 \mu \mathrm{g} / \mathrm{ml})$ and TNF $(20 \mathrm{ng} / \mathrm{ml})$ for various times, ranging from 0 to $120 \mathrm{~min}, 1 \times 10^{7}$ cells per sample. Lipids were extracted and resuspended with $\mathrm{C} 2: 0$ ceramide added to $200 \mathrm{fmol} / \mu \mathrm{l}$ as an internal standard prior to analysis by PIS. Signal intensities of peaks corresponding to each ceramide species (indicated in Figure 2) were summed and ratios to the $\mathrm{C} 2: 0$ internal standard signal calculated. Mean values for each time point were calculated along with standard deviations and are displayed graphically ( $n=3$, except 0 and 5 min time points where $n=2$ ). The three most abundant ceramides present in U937 cells (see Figure 2) are shown: the C16:0, C24:1 and C24:0, as indicated. Control samples (Ctl) were cells treated for 120 min with $\mathrm{CHX}$ alone any detectable increases in the level of any quantifiable ceramide species present in HL-60 cells until 60 min poststimulation (Figure 5). However, unlike we had observed in U937 cells treated with TNF and $\mathrm{CHX}$, all detectable ceramides were found to increase in level to roughly the same degree and with roughly the same kinetics following the addition of Aniso. At 240 min post-stimulation, most ceramides had approximately doubled in level compared with the unstimulated control. On the other hand, in contrast with our observations with either TNF or Aniso, treatment with GG produced almost no detectable increases in ceramide levels until 240 min post-stimulation (Figure 6). The level of the major ceramide species present in HL-60 cells, the C16:0, was only very slightly elevated at $60 \mathrm{~min}$, and a little more so at $120 \mathrm{~min}$, but was almost threefold higher at $240 \mathrm{~min}$, compared with the unstimulated control. A similar profile to this was observed with $G G$ for the C24:1. In contrast, we found that C24:0 levels did not significantly change for the duration of the experiment.

In order to confirm apoptotic induction in HL-60 cells with Aniso and GG, additional cell lysates were made from identically treated cells and immunoblotted for caspase-3. As can be seen from Figure 7, cleavage of caspase-3 was
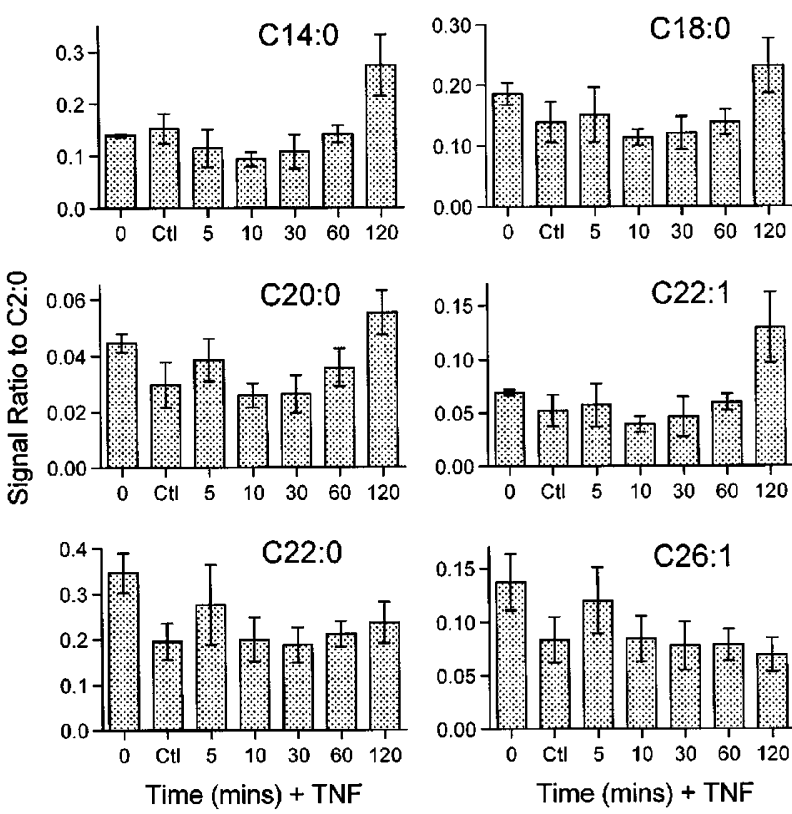

Figure 4 Variation of the minor cellular ceramide species in U937 cells stimulated with TNF and cycloheximide. U937 (at $2 \times 10^{6} / \mathrm{ml}$ ) were treated with $\mathrm{CHX}(1 \mu \mathrm{g} / \mathrm{ml})$ and TNF $(20 \mathrm{ng} / \mathrm{ml})$ for various times, ranging from 0 to $120 \mathrm{~min}$, $1 \times 10^{7}$ cells per sample (same data set as in Figure 3 ). Lipids were extracted and resuspended with $\mathrm{C} 2: 0$ ceramide added to $200 \mathrm{fmol} / \mu \mathrm{l}$ as an internal standard prior to analysis by PIS. Signal intensities of peaks corresponding to each ceramide species (indicatged in Figure 2) were summed and ratios to the C2:0 internal standard signal calculated. Mean values for each time point were calculated along with standard deviations and are displayed graphically ( $n=3$, except 0 and 5 min time points where $n=2$ ). The six most apparent minor ceramides species present in U937 cells (see Figure 2) are shown: the $\mathrm{C} 14: 0$, $\mathrm{C} 18: 0, \mathrm{C} 20: 0, \mathrm{C} 22: 1, \mathrm{C} 22: 0$ and $\mathrm{C} 26: 1$, as indicated. Control. samples (Ctl) were cells treated for $120 \mathrm{~min}$ with $\mathrm{CHX}$ alone 
evident 60 min post-stimulation with Aniso, indicating that the cells are again entering the late stages of apoptosis at 60 min post-treatment. GG on the other hand produced marked cleavage of caspase-3 at $60 \mathrm{~min}$, with almost no intact enzyme remaining at $120 \mathrm{~min}$. Interestingly, the kinetics of caspase-3 cleavage observed following treatment with either Aniso or GG were quite different from the induced kinetics of ceramide production. However, as with the TNF and CHX treatment of U937 cells, it can again be concluded from Figures 5-7 that there was no generation of any ceramides in response to either Aniso or GG until the HL-60 cells were well advanced in the apoptotic process, an observation which was particularly apparent in the case of GG treatment.

\section{Discussion}

Until recently, changes in cellular ceramides have been quantified either by some form of in vivo metabolic radiolabeling of the ceramide/sphingomyelin biosynthetic pathway, or more typically, by what is normally referred to as the diacylglycerol (DAG) kinase assay. This assay relies on the phosphorylation of biological lipid preparations with an
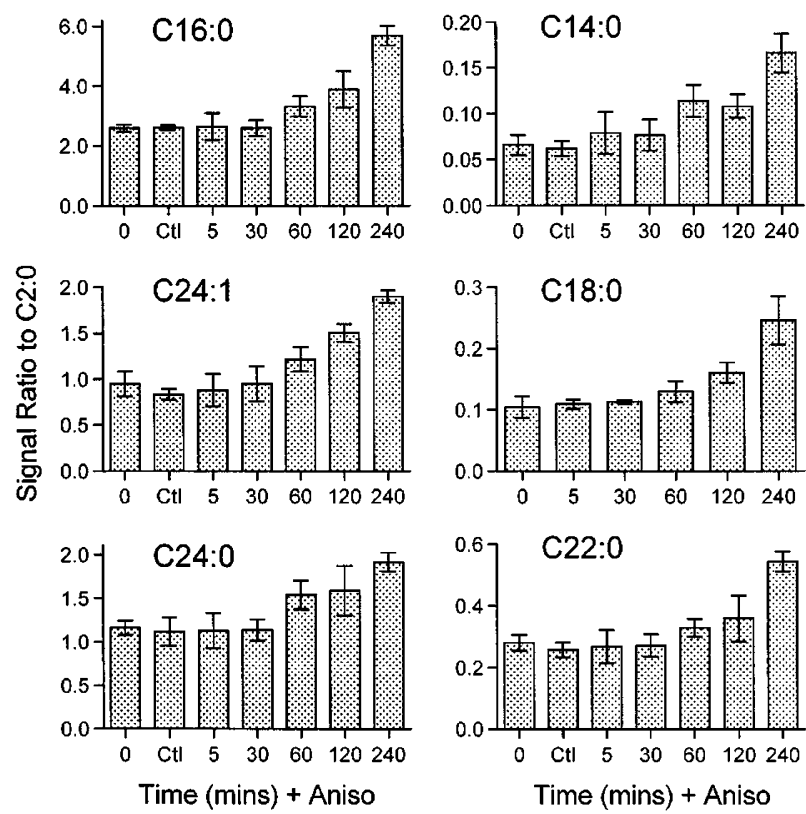

Figure 5 Variation of the predominant cellular ceramide species in HL-60 cells stimulated with anisomycin. HL-60 (at $1 \times 10^{6} / \mathrm{ml}$ ) were treated with Aniso $(1 \mu \mathrm{g} / \mathrm{ml})$ for various times, ranging from 0 to $240 \mathrm{~min}, 1.2 \times 10^{7}$ cells per sample. Lipids were extracted and resuspended with $\mathrm{C} 2: 0$ ceramide added to $200 \mathrm{fmol} / \mu \mathrm{l}$ as an internal standard prior to analysis by PIS. Signal intensities of peaks corresponding to each ceramide species were summed and ratios to the C2: 0 internal standard signal calculated. Mean values for each time point were calculated along with standard deviations and are displayed graphically ( $n=4$, except 0 time point where $n=3$ ). The three most abundant ceramides present in HL-60 cells ${ }^{24}$ are shown: C16:0, C24:1 and C24:0 (on the left) as well as the three most dominant minor ceramide species: C14:0, C18:0 and $\mathrm{C} 22: 0$ (on the right), as indicated. Control samples (Ctl) were treated identically for $240 \mathrm{~min}$ in the absence of Aniso
E. ColiDAG kinase, producing phospho-ceramide as one of a number of products. Both radiolabeling experiments and DAG kinase assays then require the subsequent separation and visualization of labeled products on one-dimensional silica TLC plates, with ceramide identity being inferred by mobility comparisons with appropriate commercially available standards.

There are a number of technical limitations with such conventional ceramide assays. Firstly, they are only able to provide information on the total ceramide content of the cells in question, yielding essentially no information about
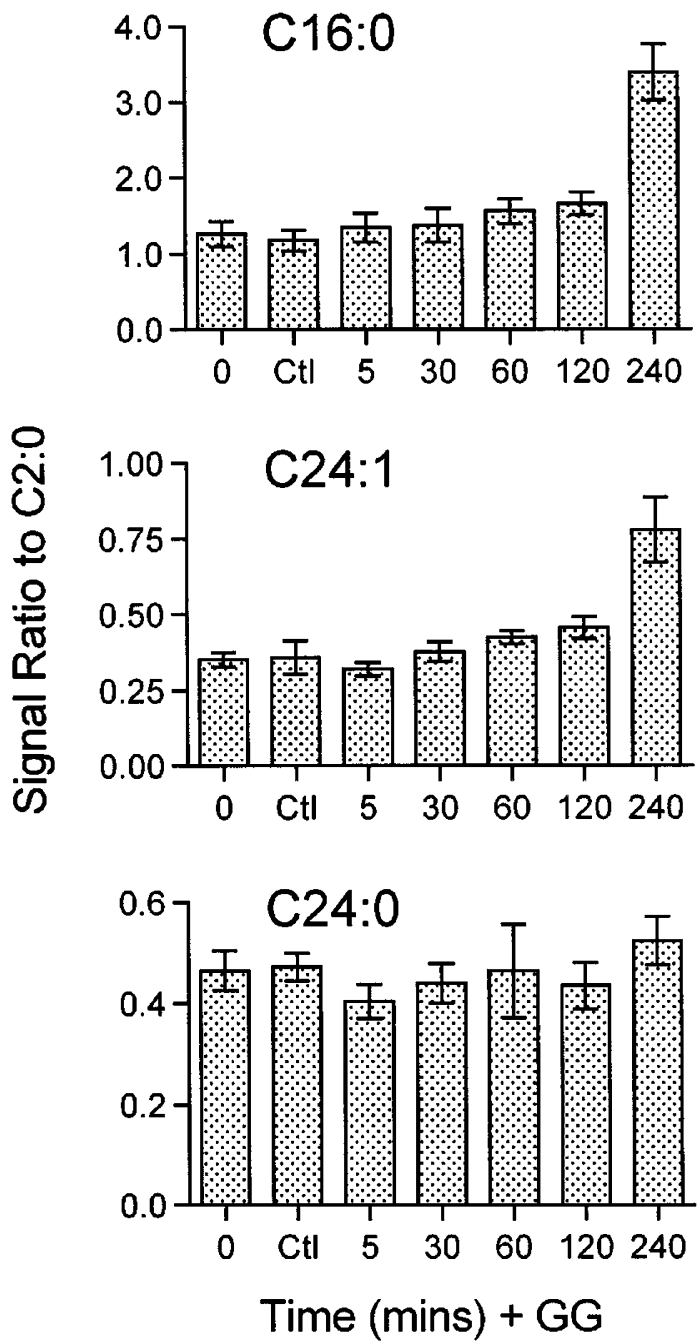

Figure 6 Variation of the predominant cellular ceramide species in HL-60 cells stimulated with geranylgeraniol. HL-60 (at $1 \times 10^{6} / \mathrm{ml}$ ) were treated with $\mathrm{GG}(10 \mu \mathrm{M})$ for various times, ranging from 0 to $240 \mathrm{~min}, 1.2 \times 10^{7}$ cells per sample. Lipids were extracted and resuspended with $\mathrm{C} 2: 0$ ceramide added to $200 \mathrm{fmol} / \mu \mathrm{l}$ as an internal standard prior to analysis by PIS. Signal intensities of peaks corresponding to each ceramide species were summed and ratios to the $\mathrm{C} 2: 0$ internal standard signal calculated. Mean values for each time point were calculated along with standard deviations and are displayed graphically $(n=3)$. The three most abundant ceramides present in HL-60 cells ${ }^{24}$ are shown: C16:0, C24:1 and C24:0, as indicated. Control samples (Ctl) were treated identically for $240 \mathrm{~min}$ in the absence of $\mathrm{GG}$ 


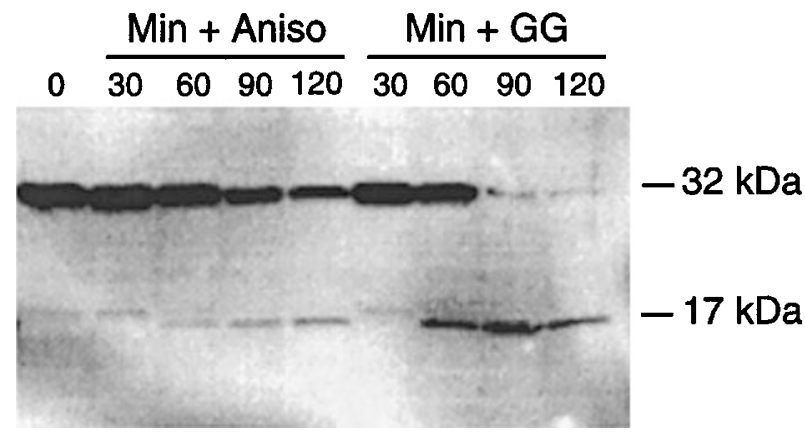

Figure 7 Cleavage of caspase- 3 in $\mathrm{HL}-60$ cells stimulated with anisomycin or geranylgeraniol. HL-60 (at $1 \times 10^{6}$ cells $/ \mathrm{ml}$ ) were treated with Aniso $(1 \mu \mathrm{g} /$ $\mathrm{ml}$ ) or $\mathrm{GG}(10 \mu \mathrm{M})$ for various times, ranging from 0 to $120 \mathrm{~min}, 5 \times 10^{6}$ cells per sample. Cell lysates were prepared as described in Materials and Methods. Lysates equivalent to $1 \times 10^{6}$ cells were subjected to SDS-PAGE on $12 \%$ gels prior to transfer to nitrocellulose membranes. Immunoblotting was performed with anti-caspase- 3 mAbs as described in Materials and Methods. Visualization was by ECL. Bands corresponding to the full length and cleaved forms of caspase- 3 ( 32 and $17 \mathrm{kDa}$ ) are indicated

individual ceramide species. Secondly, they are dependent on the assumption that the spots being quantified are indeed ceramide or ceramide-derived (depending on the assay used). Since only a very small fraction of cellular lipid preparations actually constitute ceramide, this would seem to be a concern. Indeed, even after purifying ceramides on silica gel columns (a process very similar to TLC separation), we have found by both MS and TLC analysis that the vast majority of the lipids recovered are still not the sphingosine-based ceramides of interest ${ }^{24}$ (and J. Watts, unpublished data). We have also recently provided strong evidence that not only are there one or more natural products present in cellular lipid preparations that can alter the specific activity of the E. coli DAG kinase during an assay, but that its specific activity can be increased further when working with stimulated cell extracts. ${ }^{25}$ Such serious concerns thus cast doubt on any past conclusions about in vivo ceramide generation which have relied on the DAG kinase assay.

The MS-based assay we have employed in this study provides an elegant solution to these limitations. Firstly, despite the complexity of the lipid extracts being analyzed, PIS displays only the sphingosine-based ceramide-derived signals of interest. We have found that the $m / z \approx 264$ fragment ion monitored, at least as far as the biological lipid preparations we have thus far studied are concerned, is diagnostic for this class of lipids ${ }^{24,25}$ (and M. Gu, unpublished observations). Secondly, since they differ in mass, individual ceramide species can effectively be quantified simultaneously, revealing changes in species distribution should they occur. This method also has the benefit of measuring ceramides directly, without the need for enzymatic assays and multiple lipid extractions. MS is also inherently very sensitive, being able to detect ceramides in a mixture at low $\mathrm{nM}$ concentrations. The C2:0 internal standard employed in these studies is added to a concentration of $200 \mathrm{fmol} / \mu \mathrm{l}(200 \mathrm{nM})$, and as is clear from Figures 2 and 4, we still are able to visualize and quantitate ceramide species present at levels more than tenfold lower than this (e.g. $20 \mathrm{nM}=20 \mathrm{fmol} / \mu \mathrm{l}=10.8 \mathrm{pg} / \mu \mathrm{l}$ of C16: 0 ceramide). ${ }^{24}$ Since lipids are also analyzed following minimal sample handling steps, such sensitivity thus translates into the ability to perform ceramide quantitations from relatively low numbers of cells. In this study, for example, the PIS data from the TNF-stimulated U937 cells presented in Figures 2-4 were acquired from the analysis of lipids extracted from a total of $\sim 2.5 \times 10^{5}$ cells (per sample), and we were still able to adequately evaluate very minor ceramide species.

It has been generally stated in the literature that ceramides function as second messengers for apoptosis. We can thus assume, as is the case with other well known second messengers (e.g. cyclic AMP and DAG), that ceramide levels would rise somewhat rapidly upon appropriate cell stimulation if they were fulfilling such a role. Indeed such increases have been widely reported using the more traditional methods for ceramide quantitation. However, in our previous studies on ceramide generation during apoptosis induced by Fas, ${ }^{25}$ and in this study by TNF, Aniso and GG, we have each time failed to detect any rapid perturbation in either total ceramide quantity or the relative distribution of the different species. These findings would appear to contradict such literature.

Recently, however, a number of other groups have also reported a lack of rapid ceramide generation during apoptotic induction. These studies have examined apoptotic induction via Fas, ${ }^{29-31} \mathrm{TNF}^{29}$ and ionizing radiation. ${ }^{32}$ Such rapid ceramide generation, at least in the case of TNF signaling, had also been postulated to be due to the action of membrane-bound Smases, which had been shown to become activated within the first few minutes of TNF treatment. $^{12,13}$ However, the recent availability of acidic SMase deficient mice and cell lines, and the recent cloning of the gene for neutral SMase have permitted more thorough investigations of a potential requirement for these enzymes during apoptosis. These studies also found that responses to TNF occurred independently of SMase gene expression and ceramide generation. ${ }^{33-35}$ Such inconsistencies in the data have subsequently led to doubts being expressed as to the relevance of ceramides as second messengers for apoptosis. ${ }^{36}$ Additionally, it has also very recently been shown that the cell permeable artificial $\mathrm{C} 2: 0$ ceramide, frequently used experimentally as a mimic for this so-called ceramide-induced apoptosis, affects both lipid bilayer structures and phospholipase activity quite differently from the non-cell permeable $\mathrm{C} 16: 0$ natural ceramide. ${ }^{37}$

There could be many reasons why such inconsistencies in the published literature exist. However, as was discussed briefly above, much of this may be attributable to the analytical methodologies employed for the quantitation of biological ceramides. If only total ceramide content is measured, with no discrimination between individual species, then as our MS data show, in HL-60, U937 Jurkat cells at least, the results would essentially depend on $\mathrm{C} 16: 0$ levels since it is clearly the dominant ceramide species in these cell lines (see Figure 2). ${ }^{24,25}$ As can be seen from Figure 2, a several-fold increase in one of the 
minor ceramide species would constitute only a fractional increase in total ceramide. Such changes are clearly visualized by MS, but due to inherent experimental variations, would be indeterminable by conventional assays, which would in any case be unable to identify the species of interest.

The work presented here shows that, insofar as we have been able to determine, ceramide generation does not occur as an early signal in the induction of apoptosis. Certainly there are no ceramide increases observable in the first few minutes following cell stimulation, as is typically observed for acknowledged second messengers such as DAG and calcium, for example. However, changes in ceramide levels are evident late in apoptosis, changes we found to in fact be quite complex, and indeed quite different and subtle. We have observed responses which have varied between no ceramide generation whatsoever, as in the case of $\mathrm{Fas}^{25}$ to a gradual accumulation of all ceramide species, as in the case of Aniso. The results with TNF and GG, however, reveal that subtle changes in the distribution of the minor ceramide species can also occur under certain conditions, and that these distributions can also vary from one treatment to the next.

Since it is only recently that the harnessing of the great specificity and sensitivity afforded by MS to the study of ceramide generation in vivo ${ }^{24,25,38}$ has provided the opportunity to investigate such matters, one can still only speculate as to the significance of our current findings. Clearly they pose many as yet unanswered questions about the role certain ceramide species might be playing the late stages of apoptotic induction. For example, these data may provide new insight into the study of the ceramide biosynthetic enzymes, both sphingomyelinases and ceramide synthases, and their substrate specificities. As the nucleic acids and proteins are degraded as the cell dies, these data pose questions as to whether, and if so how, cellular lipids are also broken down at this time. It is also quite reasonable to suggest from these data that one or more ceramide species may yet be found to play an important role in the determination of the late stages of apoptosis. However, it would seem clear that the utilization of the newer and more powerful MS-based methodologies is essential in any future studies aimed at addressing the potential role of ceramides in these late stages of apoptosis, or any other process for that matter, in order to answer such questions adequately.

\section{Materials and Methods}

\section{Chemicals and reagents}

All cell culture media and supplements were from GIBCO BRL (Rockville, MD, USA) unless, otherwise noted. Anti-PARP monoclonal antibody (mAb) was from Biomol Inc. (Plymouth, PA, USA). Anticaspase-3 mAb was from Transduction Laboratories (Lexington, $\mathrm{KY}$, USA). Anti-caspase-8 mAb was from Pharmingen Inc. (San Diego, CA, USA). Actin-actin goat polyclonal Ab (I-19) was from Santa Cruz Biotechnology Corp. (Santa Cruz, CA, USA). Goat anti-mouse peroxidase conjugated secondary antibodies were from GIBCO BRL (Grand Island, NY, USA) and rabbit anti-goat peroxidase conjugated secondary antibodies were from Calbiochem (San Diego, CA, USA). Dithiothreitol (DTT), soybean trypsin inhibitor (STI), pepstatin, leupeptin, aprotinin, cycloheximide, anisomycin and geranylgeraniol were from Sigma-Aldrich (St. Louis, MO, USA). N-acetyl-D-erythrosphingosine (C2:0 ceramide) and recombinant human TNF $\alpha$ were from Calbiochem. Phenylmethylsulfonyl fluoride (PMSF) was from Boehringer Mannheim (Indianapolis, IN, USA). Nitrocellulose membranes were from Schleicher \& Schuell (Keene, NH, USA). Enhanced chemiluminescence (ECL) reagents were from Amersham (Arlington Heights, IL, USA) and X-OMAT film from Kodak (Rochester, NY, USA).

\section{Cell culture and stimulation}

U937 cells were maintained in RPMI 1640 with fetal calf serum added to $10 \%$, supplemented with L-glutamine, MEM sodium pyruvate and 2 mercaptoethanol. Cells were stimulated in $120 \mathrm{~mm}$ petri dishes in the above medium at $2 \times 10^{6} \mathrm{cell} / \mathrm{ml}$ and at $37^{\circ} \mathrm{C}$. For cell stimulation, $\mathrm{CHX}$ was added to a final concentration of $1 \mu \mathrm{g} / \mathrm{ml}$ and TNF to $20 \mathrm{ng} / \mathrm{ml}$. Dishes were returned to the incubator for varying lengths of time, after which cell pellets were harvested by centrifugation at 2000 r.p.m. for $2 \mathrm{~min}$ at room temperature.

HL-60 cells were maintained and stimulated with either Aniso or $\mathrm{GG}$ as previously described. ${ }^{20}$

\section{Immunoblotting}

For PARP immunoblotting, U937 total cell lysates were prepared by direct sonication in $62.5 \mathrm{mM}$ Tris $\mathrm{pH} 6.8,20 \%$ glycerol $(\mathrm{v} / \mathrm{v}), 4 \mathrm{M}$ urea, $2 \%$ SDS (w/v), $10 \mathrm{mM}$ DTT, $5 \mathrm{mM}$ EDTA, 0.02\% bromophenol blue $(\mathrm{w} / \mathrm{v})$. Aliquots were run on $8 \%$ SDS gels prior to electroblotting to nitrocellulose in $25 \mathrm{mM}$ Tris $\mathrm{pH} 8.8,192 \mathrm{mM}$ glycine, $20 \%$ methanol $(\mathrm{v} / \mathrm{v})$. Membranes were blocked for $4 \mathrm{~h}$ in $5 \% \mathrm{BSA}(\mathrm{w} / \mathrm{v})$ in TBST buffer (25 mM Tris pH 8, $150 \mathrm{mM} \mathrm{NaCl}, 0.05 \%$ Tween-20). Blots were developed sequentially with anti-PARP $\mathrm{mAb}(1: 5000)$ for $2 \mathrm{~h}$ and goat anti-mouse-peroxidase $(1: 10000)$ for $1 \mathrm{~h}$ in $1 \%$ BSA in TBST, washing blots extensively with TBST following each antibody step. Visualization was by ECL.

For caspase-3 and caspase-8 immunoblotting, U937 cell lysates were prepared by sonication in $1 \%$ Triton X-100 (v/v), $25 \mathrm{mM}$ Tris $\mathrm{pH}$ 7.5, $150 \mathrm{mM} \mathrm{NaCl}, 2 \mathrm{mM}$ EDTA, $1 \mathrm{mM}$ DTT, $1 \mathrm{mM} \mathrm{PMSF}, 10 \mu \mathrm{g} /$ $\mathrm{ml} \mathrm{STI}, 2.5 \mu \mathrm{g} / \mathrm{ml}$ pepstatin, $1 \mu \mathrm{g} / \mathrm{ml}$ leupeptin, $1 \mu \mathrm{g} / \mathrm{ml}$ aprotinin. Lysates were centrifuged for $5 \mathrm{~min}$ at $4^{\circ} \mathrm{C}$ and the supernatants recovered. Aliquots were run on $15 \%$ SDS gels prior to electroblotting to nitrocellulose. Immunoblots were developed and visualized exactly as for PARP above, except that the anti-caspase mAbs were used at a concentration of $0.5 \mu \mathrm{g} / \mathrm{ml}$.

For actin immunoblotting, the caspase-8 blot was gently stripped overnight in $100 \mathrm{mM}$ glycine, $0.5 \%$ Tween-20, pH 2. Following rinsing in TBST buffer, the blot was developed as for PARP above, except that the blocking step was reduced to $1 \mathrm{~h}$ only, the anti-actin $\mathrm{Ab}$ was used at a concentration of $0.1 \mu \mathrm{g} / \mathrm{ml}$ for $1 \mathrm{~h}$ only, and the secondary $\mathrm{Ab}$ (rabbit anti-goat-peroxidase) was used at a dilution of 1:50 000, also for $1 \mathrm{~h}$ only.

$\mathrm{HL}-60$ lysates were prepared and immunoblots performed exactly as described previously. ${ }^{20}$

\section{Lipid extraction and mass spectrometry}

Lipid extraction from cell pellets and mass spectrometric analyses were performed as previously described. ${ }^{24,25}$ 
In brief, cell pellets were resuspended by sonication in $1 \mathrm{ml}$ $\mathrm{CH}_{3} \mathrm{OH} / \mathrm{H}_{2} \mathrm{O} / 12 \mathrm{M} \mathrm{HCl}$ 95:5:0.5 (v/v). Lipids were prepared by partitioning into $\mathrm{CHCl}_{3}$, following the addition of 0.6 volumes of icecold water and 1 volume of $\mathrm{CHCl}_{3}$. Organic phases were recovered and dried in glass tubes. Ceramides were separated from polar lipids using disposable, small silica gel chromatography columns, run in $\mathrm{CHCl}_{3} / \mathrm{CH}_{3} \mathrm{OH}(95: 5 \mathrm{v} / \mathrm{v})$. One large fraction, spanning the known elution positions for ceramides varying from $\mathrm{C} 2: 0$ to $\mathrm{C} 24: 1$ was collected and dried down. Samples were frozen at $-80^{\circ} \mathrm{C}$ prior to analysis.

The dried lipid mixtures were typically resuspended in $200 \mu \mathrm{l}$ $\left(\sim 5 \times 10^{4}\right.$ cells $/ \mu$ l) of $5 \mathrm{mM}$ ammonium acetate in $\mathrm{CH}_{3} \mathrm{OH}$, with $\mathrm{C} 2: 0$ ceramide added to $200 \mathrm{fmol} / \mu \mathrm{l}$ as an internal standard. Samples were then infused into a Finnigan MAT TSQ 7000 mass spectrometer via a Harvard Apparatus at a flow-rate of $1 \mu \mathrm{l} / \mathrm{min}$. This provided plenty of time to collect as much data as was required for each sample. Mass analysis was performed at a heated capillary tube temperature of $200^{\circ} \mathrm{C}$, an electrospray potential of $4.5 \mathrm{kV}$ and a sheath gas pressure of 45 p.s.i. A collision gas (argon) pressure of $1 \mathrm{mtorr}$ was used when scanning in PIS mode. Individual scans were collected over a preset 5 min time window and averaged. Since only a relatively small fraction of the material was required for the analysis, the remainder was stored at $-80^{\circ} \mathrm{C}$ in small, tightly sealed glass vials to permit re-analysis when necessary and to serve as machine performance standards as required. Data processing, analysis and presentation has been discussed elsewhere. ${ }^{24,25}$

\section{Acknowledgements}

This work was supported in part by the National Science Foundation Science and Technology Center for Molecular Biotechnology at the University of Washington, and by a research grant from the National Institutes of Health to R.A. (\#1RO1 A1 41109-01).

\section{References}

1. Ameisen JC (1996) The origin of programmed cell death. Science 272: 1278 1279

2. Hale AJ, Smith CA, Sutherland LC, Stoneman VE, Longthorne VL, Culhane AC and Williams GT (1996) Apoptosis: molecular regulation of cell death. Eur. J. Biochem. 236: 1-26.

3. Merrill Jr, AH, Schmelz EM, Dillehay DL, Spiegel S, Shayman JA, Schroeder JJ, Riley RT, Voss KA and Wang E (1997) Sphingolipids - the enigmatic lipid class: biochemistry, physiology, and pathophysiology. Toxicol. Appl. Pharmacol. 142: $208-225$

4. Hannum YA (1996) Functions of ceramide in coordinating cellular responses to stress. Science 274: $1855-1859$

5. Kolesnick RN and Krönke M (1998) Regulation of ceramide production and apoptosis. Ann. Rev. Physiol. 60: 643-665

6. Dbaibo GS, Obeid LM and Hannun YA (1993) Tumor necrosis factor-alpha (TNFalpha) signal transduction through ceramide. Dissociation of growth inhibitory effects of TNF-alpha from activation of nuclear factor-kappa B. J. Biol. Chem. 268: $17762-17766$

7. Yang Z, Costanzo M, Golde DW and Kolesnick RN (1993) Tumor necrosis factor activation of the sphingomyelin pathway signals nuclear factor kappa $B$ translocation in intact HL-60 cells. J. Biol. Chem. 268: 20520-20523

8. Gulbins E, Bissonnette R, Mahboubi A, Martin S, Nishioka W, BrunnerT, Baier G, Baier-Bitterlich G, Byrd C, Lang F, Kolesnick R, Altman A and Green D (1995) FAS-induced apoptosis is mediated via a ceramide-initiated RAS signaling pathway. Immunity 2: $341-351$

9. Gulbins E, Szabo I and Lang F (1996) Physiology of Fas-induced programmed cell death. Cell. Physiol. Biochem. 6: 361-375
10. Tepper CG, Jayadev S, Liu B, Bielawska A, Wolff R, Yonehara S, Hannun YA and Seldin MF (1995) Role for ceramide as an endogenous mediator of Fas-induced cytotoxicity. Proc. Natl. Acad. Sci. USA 92: 8443-8447

11. Kuno K and Matsushima K (1994) The IL-1 receptor signaling pathway. J. Leuk. Biol. 56: $542-547$

12. Krönke M, Schütze S, Wiegmann K and Machleidt T (1996) Sphingomyelinases and TNF-induced apoptosis. Cell. Physiol. Biochem. 6: $337-344$

13. Wiegmann K, Schütze S, Machleidt T, Witte D and Krönke M (1994) Functional dichotomy of neutral and acidic sphingomyelinases in tumor necrosis factor signaling. Cell 78: 1005-1015

14. Haimovitz-Friedman A, Kan C-C, Ehleiter D, Persaud RS, McLoughlin M, Fuks Z and Kolesnick RN (1994) lonizing radiation acts on cellular membranes to generate ceramide and initiate apoptosis. J. Exp. Med. 180: 525-535

15. Martin SJ, Newmeyer DD, Mathias S, Farschon DM, Wang HG, Reed JC, Kolesnick RN and Green DR (1995) Cell-free reconstitution of Fas-, UV radiationand ceramide-induced apoptosis. EMBO J. 14: 5191-5200

16. Verheij M, Bose R, Lin XH, Yao B, Jarvis WD, Grant S, Birrer MJ, Szabo E, Zon LI, Kyriakis JM, Haimovitz-Friedman A, Fuks Z and Kolesnick RN (1996) Requirement for ceramide-initiated SAPK/JNK signalling in stress-induced apoptosis. Nature 390: 75-79

17. Bose R, Verheij M, Haimovitz-Friedman A, Scotto K, Fuks Z and Kolesnick R (1995) Ceramide synthase mediates daunorubicin-induced apoptosis: An alternative mechanism for generating death signals. Cell 82: 405-414

18. Jaffrézou JP, Levade T, Bettaïeb A, Andrieu N, Bezombes C, Maestre N, Vermeersch S, Rousse A and Laurent G (1996) Daunorubicin-induced apoptosis: Triggering of ceramide generation through sphingomyelin hydrolysis. EMBO J. 15: 2417-2424

19. Faris M, Kokot N, Latinis K, Kasibhatla S, Green DR, Koretzky GA and Nel A (1998) The c-Jun N-terminal kinase cascade plays a role in stress-induced apoptosis in Jurkat cells by up-regulating Fas ligand expression. J. Immunol. 160: $134-144$

20. Polverino AJ and Patterson SD (1997) Selective activation of caspases during apoptotic induction in HL-60 cells. J. Biol. Chem. 272: 7013-7021

21. Masuda Y, Nakaya M, Nakajo S and Nakaya K (1997) Geranylgeraniol potently induces caspase-3-like activity during apoptosis in human leukemia U937 cells. Biochem. Biophys. Res. Commun. 234: 641-645

22. Ohizumi H, Masuda Y, Nakajo S, Sakai I, Ohsawa S and Nakaya K (1995) Geranylgeraniol is a potent inducer of apoptosis in tumor cells. J. Biochem. 117: $11-13$

23. Voziyan PA, Haug JS and Melnykovych G (1995) Mechanism of farnesol cytotoxicity: further evidence for the role of PKC-dependent signal transduction in farnesol-induced apoptotic cell death. Biochem. Biophys. Res. Comm. 212: $479-486$

24. Gu M, Kerwin JL, Watts JD and Aebersold R (1997) Ceramide profiling of complex lipid mixtures by electrospray ionization mass spectrometry. Anal. Biochem. 244: 347-356

25. Watts JD, Gu M, Polverino AJ, Patterson SD and Aebersold R (1997) Fasinduced apoptosis of T cells occurs independently of ceramide generation. Proc Natl. Acad. Sci. USA 94: 7292-7296

26. Baichwal VR and Baeuerle PA (1997) Apoptosis: Activate NF-kappaB or die? Curr. Biol. 7: R94-R96

27. Cohen GM (1997) Caspases: the executioners of apoptosis. Biochem. J. 326: $1-16$

28. Kidd VJ (1998) Proteolytic activities that mediate apoptosis. Ann. Rev. Physiol. 60: $533-573$

29. Gamen S, Anel A, Piñeiro A and Naval J (1998) Caspases are the main executioners of Fas-mediated apoptosis, irrespective of the ceramide signalling pathway. Cell Death Differ. 5: 241-249

30. Hsu S-C, Wu C-C, Luh T-Y, Chou C-K, Han S-H and Lai M-Z (1998) Apoptotic signal of Fas is not mediated by ceramide. Blood 91: 2658-2663

31. Sillence DJ and Allan D (1997) Evidence against an early signalling role for ceramide in Fas-mediated apoptosis. Biochem. J. 324: 29-32

32. Bruno AP, Laurent G, AverbeckD, Demur C, Bonnet J, Bettaïeb A, Levade T and Jaffrézou JP (1998) Lack of ceramide generation in TF-1 human myeloid leukemic cells resistant to ionizing radiation. Cell Death Differ. 5: 172-182

33. AdamD, Ruff A, Strelow A, Wiegmann Kand KrönkeM(1998) Induction of stressactivated protein kinases/c-jun $\mathrm{N}$-terminal kinases by the p55 tumour necrosis factor does not require sphingomyelinases. Biochem. J. 333: 343-350 
34. Tomiuk S, Hofmann K, Nix M, Zumbansen M and Stoffel W (1998) Cloned mammalian neutral sphingomyelinase: functions in sphingolipid signaling? Proc. Natl. Acad. Sci. USA 95: 3638-3643

35. Zumbansen M and Stoffel W (1997) Tumor necrosis factor $\alpha$ activates NF- $\kappa$ B in acid sphingomyelinase-deficient mouse embryonic fibroblasts. J. Biol. Chem. 272: $10904-10909$

36. Schulze-Osthoff K, Ferrari D, Los M, Wesselborg S and Peter ME (1998) Apoptosis signaling by death receptors. Eur. J. Biochem. 254: 439-459
37. Huang H-W, Goldberg EM and Zidovetzki R (1998) Ceramides perturb the structure of phosphatidylcholine bilayers and modulate the activity of phospholipase A2. Eur. Biophys. J. 27: 361-366

38. Mano N, Oda Y, Yamada K, Asakawa N and Katayama K (1997) Simultaneous quantitative determination method for sphingolipid metabolites by liquid chromatography/ionspray ionization tandem mass spectrometry. Anal. Biochem. 244: 291-300 